\title{
Male Academy rugby union student-athletes in-season physical anthropometrical and physical performance changes, and comparisons with available data
}

\author{
N Rishiraj1, PhD, ATC; B Niven², MSC \\ ${ }^{1}$ ACTIN Health $\mathcal{E}$ Rehabilitation Inc., Vancouver, BC, Canada \\ 2 Department of Mathematics \& Statistics, University of Otago, Dunedin, \\ New Zealand
}

\section{Corresponding author: N Rishiraj (nrishiraj@actinhealth.com)}

Background: Physical performance demands of the rugby union (RU) game have increased over the past two decades. However, there are little data on these variables concentrating on developing RU players (student-athletes) over a competitive season.

Objectives: To investigate the potential enhancement of two physical anthropometrical and nine physical performance variables of male New Zealand RU Academy student-athletes over a competitive season and compare with similar published data.

Methods: Twenty student-athletes were recruited to the Otago Rugby Football Union (ORFU) two-year Academy Programme. Each week the student-athletes engaged in 25 hours of strength and conditioning training and participated in 15 hours of on-field rugby training with their respective ORFU Premier League team. Assessments sessions were scheduled for the start of the season, in-season, and pre-playoffs (week 31).

Results: Mean data from 20 student-athletes demonstrated a trivial effect size (ES) increase in body weight and skinfold measurements, while a paired t-test $(p<0.05)$ resulted in concurrent significant improvements in lower-body power (ES = large), acceleration (ES = large), speed (10 m sprint, ES = small, $40 \mathrm{~m}$ sprint, ES = small), and upper body strength (bench press, ES = large and bench pull, ES = small). A nonsignificant physical performance improvement, with trivial ES difference, was also noted in anaerobic endurance performance.

Conclusion: Based on these data significant physical performance enhancements were observed during in-season Premier League competition while limiting fatigue and overtraining.

Keywords: aerobic, anaerobic, athlete development, skinfolds, strength

\section{S Afr J Sports Med 2018;30:1-5. DOI: 10.17159/2078-516X/2018/v30i1a5577}

Since 1871, rugby union (RU),15-a-side, has maintained a long and distinguished history, including being recognised as a Summer Olympic Games medal sport in 1900, 1908, 1920, and 1924. The Men's RU joined the professional ranks in 1995 and is now played in Argentina, France, Japan, Oceania, South Africa, and the United Kingdom. On RU gaining professional status, the physiological demands of the game have increased, specifically the greater number of collisions, passes, rucks, tackles, tries, and ball-in-play time/work-rest ratio. ${ }^{[1]}$ To overcome the physiological RU game demands, prevention of injury, allowing the possibility of advancing to the professional level of play, and to enhance career longevity, RU players must start at a young age to adapt their physical stature and metabolic systems. However, there is sparse anthropometrical and physical performance data available on developing RU players. There are also no anthropometrical and/or physical performance data available on RU academy student-athletes during in-season RU competition. This information is important as it has been shown that approximately $30 \%$ of the players representing a junior national RU team advance to a senior national team. ${ }^{[2]}$

The purpose of this research was to investigate anthropometrical and physical performance changes in male New Zealand Academy student-athletes (NZASA), participating in the NZ Otago Rugby Union (ORFU) Premier League, over 31 weeks and, where possible, compare collected data with the published data from international Academy RU athletes. It is hypothesised is that NZASA anthropometrical and physical performance variables would show slight improvements over the 31-week competition season which would be similar to pre- and post-training physical performance characteristics of Academy RU athletes competing in different countries.

\section{Methods}

\section{Experimental design}

The ORFU recruited 20 student-athletes from across the nation. Ethical approval was obtained from the institutional Ethics Committee and an informed consent was received from each ORFU student-athlete. To address any potential medical concern(s), injury history and medical information was reviewed with the respective player and the ORFU Academy manager.

All NZASA were actively participating in ORFU Premier Division teams. The NZASA trained up to 25 hours per week, with an additional 15 hours scheduled for team practices and game play (Table 1). Testing sessions were periodised for the start of the season (Week 1), in-season (Week 18), and preplayoffs (Week 31) to ensure anthropometrical and physical performance data were collected from the maximum number of NZASA. All anaerobic capacity and sprint testing was completed on an indoor Balsam ProBounce sand-filled synthetic carpet surface.

\section{Subjects and anthropometrical measures}

The age range of the 20 NZASA was 19 to 21 years and the pooled (11 forwards and 9 backs) mean body weight was 92.1 $\mathrm{kg}$ with a standard deviation of $\pm 11.6 \mathrm{~kg}$. The pooled mean of the seven skinfold sites ${ }^{[3]}$ was $91.3 \mathrm{~cm} \pm 38.4 \mathrm{~cm}$. Detailed body weight and skinfold data are presented in Table 2. 
Table 1. New Zealand Academy student athlete weekly game, practice, and training schedule over the competitive season, Weeks 1 to 31

\begin{tabular}{|c|c|c|c|c|c|c|}
\hline Sunday & Monday & Tuesday & Wednesday & Thursday & Friday & Saturday \\
\hline $\begin{array}{l}\text { AM: } \\
\text { Recovery } \\
\text { Session* }\end{array}$ & $\begin{array}{l}\text { AM: } \\
\text { Weight } \\
\text { Training }\end{array}$ & $\begin{array}{l}\text { AM: } \\
\text { Core \& } \\
\text { Flexibility }\end{array}$ & $\begin{array}{l}\text { AM: } \\
\text { Weight } \\
\text { Training }\end{array}$ & $\begin{array}{l}\text { AM: } \\
\text { Core \& } \\
\text { Flexibility }\end{array}$ & $\begin{array}{l}\text { AM: } \\
\text { Activation } \\
\text { Sessiont }\end{array}$ & \\
\hline & & & $\begin{array}{l}\text { Noon: } \\
\text { Individual } \\
\text { specific } \\
\text { training }\end{array}$ & & & $\begin{array}{l}\text { GAME } \\
\text { DAY }\end{array}$ \\
\hline $\begin{array}{l}\text { PM: } \\
\text { REST }\end{array}$ & $\begin{array}{l}\text { PM: } \\
\text { Aerobic/ } \\
\text { Anaerobic } \\
\text { Training }\end{array}$ & $\begin{array}{l}\text { PM: } \\
\text { Team } \\
\text { Practice }\end{array}$ & $\begin{array}{l}\text { PM: } \\
\text { Speed and } \\
\text { Agility } \\
\text { Training }\end{array}$ & $\begin{array}{l}\text { PM: } \\
\text { Team } \\
\text { Practice }\end{array}$ & $\begin{array}{l}\text { PM: } \\
\text { REST }\end{array}$ & \\
\hline
\end{tabular}

${ }^{*}$ Recovery session consisted of aerobic, stretching, and massage (latter, budget dependant) followed by a team brunch.

tActivation session involved aerobic and flexibility activities for 30-45 minutes duration. cone was placed $20 \mathrm{~m}$ past each end of the $40 \mathrm{~m}$ sprint timing gates and NZASA were instructed to jog/walk around a cone during the 30 seconds recovery duration, but to return to the respective starting gate before the 30 seconds recovery period had elapsed. The test started from a standing start on the command for the tester. As per the acceleration and speed test, sprint elapsed time (seconds) was recorded using the Swift electronic lighting system after each $40 \mathrm{~m}$ sprint. The timing gates were set at a height of 75 $\mathrm{cm}$. A comparable repeat sprint evaluation reported a CV of $1.9 \% .^{[4]}$ NZASA performed the PDT once (10 x $40 \mathrm{~m}$ sprints). Data were expressed as follows:

\section{- PDT mean}

- Percent fatigue provided data on the fatigue rate or performance 'drop-off' over the total $400 \mathrm{~m}$ (10 $\times 40 \mathrm{~m}$ sprints) distance, and

- Percent effort involves comparing the fastest PDT sprint repeat time with the fastest $40 \mathrm{~m}$ acceleration-speed result and allows for analysis of the effort made by the respective student-athlete during the $10 \times 40 \mathrm{~m}$ sprint repeats.

An aerobic capacity test $(1500 \mathrm{~m}$ run on an outdoor rubberised $400 \mathrm{~m}$ track) was also scheduled over the three testing sessions; however, poor climate conditions negated various testing sessions.

\section{Statistical analysis}

Analysis of the changes in body weight, skinfold measurement, and physical performance levels of the NZASA over a 31-week period (Week 1 and Week 31 ) were completed using descriptive statistics (mean, SD, minimum and maximum range, and confidence intervals). Paired t-tests (Week 1 and Week 31) were performed to detect possible anthropometrical and physical performance changes over the 31-week in-season Premier League competition, with significance being determined at the $p<0.05$ level. Furthermore, the magnitude of the differences between the means was described using Cohen's effect sizes (ES) with the corresponding descriptors, trivial $=0-0.19$, small $=0.20-0.49$, medium $=0.50-0.79$, and large $=>0.80 . .^{[5]}$ Data analysis was performed using SPSS for Windows version 13.0, SPSS Inc, Chicago, Ill, USA.

\section{Results}

\section{Anthropometrical characteristics}

Body weight and skinfolds resulted in trivial increases of $0.8 \%$ and $7.4 \%$, respectively, over the 31-week Premier League competition (Table 2).

\section{Physical performance characteristics}

Significant physical performance enhancement was achieved for six physical performance variables, ranging from $0.9 \%$ to $14.6 \%$, with a large ES differences being noted for the $\mathrm{CMJ} / \mathrm{VJ}$, $5 \mathrm{~m}$ sprint and the bench press. Significant but small ES
Anaerobic endurance: Phosphate Decrement

NZASA performed $10 \times 40 \mathrm{~m}$ sprints, every 30 seconds. A 
Table 2. New Zealand Academy student-athlete physical and performance characteristics over the competitive season and comparable data

\begin{tabular}{|c|c|c|c|c|c|c|c|c|}
\hline & \multirow[t]{2}{*}{$\begin{array}{l}\text { Mean } \pm \text { SD } \\
(\% \text { Change }) \ddagger\end{array}$} & \multicolumn{2}{|c|}{ Range } & \multicolumn{2}{|c|}{$\begin{array}{l}\text { 95\% Confidence } \\
\text { Interval }\end{array}$} & \multirow[t]{2}{*}{$\begin{array}{l}\text { Cohen Effect } \\
\text { Size \& } \\
\text { (Descriptor)[9] }\end{array}$} & \multirow[t]{2}{*}{$\begin{array}{c}\text { English } \\
\text { Academy U21 } \\
\text { RU§[15] }\end{array}$} & \multirow[t]{2}{*}{$\begin{array}{l}\text { South African } \\
\text { U20 RUII | [16] }\end{array}$} \\
\hline & & Min & Max & Lower & Upper & & & \\
\hline \multicolumn{9}{|c|}{ Body weight (kg) } \\
\hline Week 1 & $92.1 \pm 11.6$ & 67.3 & 112.3 & 86.6 & 97.5 & 0.14 & $98.3 \pm 10.4$ & $92.3 \pm 8.5$ \\
\hline Week 31 & $92.8 \pm 12.6(0.8)$ & 64.6 & 115.7 & 86.9 & 98.7 & (Trivial) & & \\
\hline \multicolumn{9}{|c|}{ Skinfolds (mm)† } \\
\hline Week 1 & $91.3 \pm 38.4$ & 58.50 & 188.0 & 73.3 & 109.3 & 0.18 & $105.3 \pm 35.4$ & \\
\hline Week 31 & $98.1 \pm 35.6(7.4)$ & 52.5 & 190.0 & 81.4 & 114.7 & (Trivial) & & \\
\hline \multicolumn{9}{|c|}{ Vertical Jump / Counter } \\
\hline \multicolumn{9}{|c|}{ Movement Jump (cm)* } \\
\hline Week 1 & $55.1 \pm 7.4$ & 44.0 & 75.0 & 51.5 & 58.6 & 0.87 & $47.1 \pm 3.6$ & \\
\hline Week 31 & $61.4 \pm 7.1(11.5)$ & 52.0 & 84.0 & 58.1 & 64.7 & (Large) & & \\
\hline \multicolumn{9}{|c|}{5 Meter Sprint (s)* } \\
\hline Week 1 & $1.05 \pm 0.04$ & 1.00 & 1.20 & 1.03 & 1.08 & 1.10 & $1.07 \pm 0.07$ & \\
\hline Week 31 & $1.00 \pm 0.05(-4.4)$ & 0.90 & 1.20 & 0.98 & 1.04 & (Large) & & \\
\hline \multicolumn{9}{|c|}{10 Meter Sprint (s)* } \\
\hline Week 1 & $1.78 \pm 0.07$ & 1.70 & 2.00 & 1.75 & 1.83 & 0.71 & $1.79 \pm 0.10$ & $1.73 \pm 0.10$ \\
\hline Week 31 & $1.73 \pm 0.07(-2.8)$ & 1.60 & 1.90 & 1.70 & 1.77 & (Medium) & & \\
\hline \multicolumn{9}{|c|}{40 Meter Sprint (s)* } \\
\hline Week 1 & $5.49 \pm 0.35$ & 5.10 & 6.60 & 5.33 & 5.66 & 0.43 & $5.43 \pm 0.21$ & $5.23 \pm 0.30$ \\
\hline Week 31 & $5.36 \pm 0.24(-2.3)$ & 5.00 & 5.80 & 5.25 & 5.48 & (Small) & & \\
\hline \multicolumn{9}{|c|}{ Bench Press (kg; 1RM)* } \\
\hline Week 1 & $103.6 \pm 19.4$ & 60.0 & 139.8 & 94.5 & 112.7 & 0.80 & $108.2 \pm 14.1$ & $135 \pm 22.0$ \\
\hline Week 31 & $118.8 \pm 18.7(14.6)$ & 62.0 & 145.0 & 110.0 & 127.5 & (Large) & & \\
\hline \multicolumn{9}{|c|}{ Bench Pull (kg; 1RM)* } \\
\hline Week 1 & $87.9 \pm 10.3$ & 65.0 & 103.4 & 83.1 & 92.7 & 0.47 & $96.8 \pm 8.2$ & \\
\hline Week 31 & $92.7 \pm 10.2(5.4)$ & 67.0 & 108.9 & 88.0 & 97.5 & (Small) & & \\
\hline \multicolumn{9}{|c|}{ PDT-Mean (sec) } \\
\hline Week 1 & $5.96 \pm 0.29$ & 5.50 & 6.60 & 5.83 & 6.09 & 0.17 & & \\
\hline Week 31 & $5.91 \pm 0.30(-0.9)$ & 5.40 & 6.60 & 5.77 & 6.05 & (Trivial) & & \\
\hline \multicolumn{9}{|c|}{ PDT-Fatigue (\%) } \\
\hline Week 1 & $12.4 \pm 4.90$ & 7.50 & 27.0 & 10.1 & 14.7 & 0.05 & & \\
\hline Week 31 & $12.1 \pm 6.01(-2.3)$ & 6.40 & 25.6 & 9.32 & 14.9 & (Trivial) & & \\
\hline \multicolumn{9}{|c|}{ PDT-Effort (\%) } \\
\hline Week 1 & $93.5 \pm 4.0$ & 84.2 & 98.0 & 91.6 & 95.4 & 0.14 & & \\
\hline Week 31 & $92.8 \pm 5.8(-0.7)$ & 79.1 & 99.5 & 90.1 & 95.6 & (Trivial) & & \\
\hline
\end{tabular}

*Significant performance enhancement between Week 1 (season-start) and Week 31 (pre-play-offs) testing sessions for: Vertical Jump ( $p=0.001) ; 5$ Meter Sprint ( $p$ $=0.014) ; 10$ Meter Sprint ( $p=0.031) ; 40$ Meter Sprint ( $p=0.029)$; Bench Press $(p=0.001) ;$ Bench Pull $(p=0.003)$.

Testing sessions in Week 1 occurred in March at the start of the season. Testing sessions in Week 31 occurred in October during pre-playoffs.

tSkinfolds: Sum of seven skinfolds; an experienced nutritionist performed all skinfold tests following previous published methods.

Measurements were taken using calibrated Harpenden ${ }^{\circledR}$ Skinfold Callipers at the following sites: abdomen, chest, midaxillary, quadriceps, subscapular, suprailiac, and triceps. ${ }^{[3]}$

$\ddagger$ Percent (\%) change from Week 1 (season-start) to Week 21 (pre-playoffs).

$\S$ Data collected from fifteen U21 male English Academy RU players; playing position not specified. Authors used sum of eight site skinfolds (biceps, triceps, subscapular, suprailliac, abdominal, supraspinale, front thigh and medial calf). Data collected at 'season-start' (June) after a six week off-season training period:[15] II Data collection over 13 years from a total of 453 (forwards $=256$ and backs =197) players representing Junior (U20) South African National team. Mean data of the respective duration presented. Data collected at the 'season-start', December/January of respective season.[16]

Body mass was collected using a calibrated electronic scale ( $A$ \& D Engineering Inc.).

1RM, One repetition maximum; $R U$, Rugby Union; $R L$, Rugby League; PDT, Phosphate Decrement Test 
differences were found for the $10 \mathrm{~m}$ sprint and bench pull physical performance variables (Table 2).

\section{Discussion}

This study investigated the anthropometrical and physical performance adaptations of NZASA due to the lack of available data on developing RU student-athletes over a 31week Premier League competition.

During the 31-week season body weight of NZASA increased by $0.8 \%$ with a concurrent increase in skinfolds by $7.4 \%$. The increase in body weight is consistent with published data from Australian professional male RU players that reported annual body weight increases of $0.8 \%$ to $2.1 \%{ }^{[6]}$ However, the Australian professional male RU players experienced an annual decrease in skinfolds of between 3.9\% to $7.2 \%{ }^{[6]}$ The increase in body weight experienced by the NZASA is also supported by available literature that states that when athletes reach their adult height, their body weight continues to increase, with a simultaneous increase in lean body mass, due to continued resistance training and adequate nutrition. ${ }^{[7,8]}$ Although the higher skinfold level may offer some protection during collisions, published literature has expressed concern regarding excessive body fat as being "dead weight" and hindering a player's work rate and performance. ${ }^{[1]}$ However, even though body weight and skinfolds in the present study continued to increase, improvement was evident in all nine physical performance variables, with six variables showing significant improvements and of these six variables, a large ES difference was noted for three physical performance variables. These results would suggest that the NZASA had achieved a relatively high level of mesomorphy; an anthropometrical characteristic deemed important for elite physiological performance and good tackling ability. ${ }^{[9]}$ The mesomorphy status of the NZASA gains credibility when compared with published data from similar age RU athletes. The NZASA weighed $6.2 \mathrm{~kg}$ less and had a $14 \mathrm{~mm}$ lower skinfold measurements compared to English Academy U21 RU (EARU) athletes[10] and were of similar body weight as the South African U20 RU (SARU) athletes ${ }^{[11]}$ (Table 2).

The lower body power result achieved on Week 1 by the NZASA was superior by $8 \mathrm{~cm}$ compared to data from the EARU ${ }^{10]}$ athletes. Over the 31-week Premier League play the NZASA further recorded $11.5 \%$ significant (ES = large) lower body power performance improvement. This increase in lower body power is deemed important as previously published literature from the Rugby League (RL) has illustrated that the higher lower body power assists with the generation of greater leg drive to counter the forward progression of the opposing player during tackling. ${ }^{[9]}$

The enhanced lower body power/leg drive generation could also have contributed to the significant improvement in acceleration $(5 \mathrm{~m})$ and $10 \mathrm{~m}$ and $40 \mathrm{~m}$ speed variables in NZASA over Weeks 1-31. Since sprinting requires high force production ${ }^{[12]}$ NZASA data are consistent with published literature, which have illustrated a strong correlation between $\mathrm{VJ} / \mathrm{CMJ}$, acceleration and sprint speed over various distances (power to weight ratio).[13] As such, NZASA must have developed sufficient power output to overcome the increases in body weight and skinfolds thereby achieving significant enhancement in acceleration (large ES difference) and speed variables over the 31-week RU season.

NZASA acceleration performance at the start of the season was slower than that of the EARU athletes; ${ }^{[10]}$ however, the latter athletes had completed six weeks of training prior to their acceleration performance evaluation. The $10 \mathrm{~m}$ sprint time of the NZASA at Week 1 was marginally faster than that of the EARU $^{10]}$ athletes, but slower when compared to the SARU[11] athletes. However, it should be noted that data from the SARU athletes were recorded after the completion of one or more annual periodised training cycle(s). Data from the NZASA 40 $m$ sprint times were also slower than that from the EARU ${ }^{[10]}$ and the SARU[11] athletes respectively. However, as stated above, the faster EARU and SARU sprint times could be the result of the longer respective training durations.

Over the 31-week RU season, the NZASA recorded $14.6 \%$ and $5.4 \%$ upper body strength gains in the 1RM bench press and bench pull tests respectively. The relatively small increases in strength measures are consistent with previously published data from different football codes. For example, English RL Super League Academy U20 athletes demonstrated a small increase in strength, ${ }^{7]}$ while the American Collegiate North American football players either recorded a $4 \%$ increase, no significant change, or a loss in strength. ${ }^{[14]}$ Several other authors have attributed the low strength gains to increased capacity of concurrent aerobic and/or reduced volume of resistance training, and/or fatigue due to overtraining. ${ }^{[15]}$ It is noted that the NZASA upper body strength gains, especially for the IRM bench press, were much higher than those reported in the literature and that these higher upper body strength gains could be attributed to the cumulative training volume and stimulus, ${ }^{[16]}$ and/or the cumulative effect of improved professionalism of developing rugby players, increased emphasis on physical enhancement strategies and decreased injury risk/rates, which allowed for increased resistance training capacity/volumes. ${ }^{[8]}$ Also, the structured and supervised training sessions with continued feedback may have led to increased adherence/compliance of the NZASA, which allowed for the attainment of higher training loads and could have attributed to enhancing the NZASA 'training age'. According to published data, the enhancement in 'training age' leads to improved movement patterns, increased synchronisation of motor units and concurrent decreased antagonist muscle firing, as well as decreased inhibitory feedback mechanism all of which contribute to the production of high levels of force. ${ }^{[16]}$

The Phosphate Decrement Test (PDT) /repeated sprint test is perceived as being important in evaluating the anaerobic system required for delivering energy during a rugby competition, especially since the intensity of the RU game has increased with the inauguration of the professional Super 12 RU competition..$^{[1]}$ However, there is a lack of anaerobic data on RU players reported in the literature. ${ }^{[1]}$

During the NZASA 31-week Premier League season training duration mean sprint times over the ten repetitions of $40 \mathrm{~m}$ (PDT-mean) improved by $0.9 \%$, with a concurrent lower fatigue 
level (PDT-fatigue) by $2.3 \%$ and a $0.7 \%$ decrease in effort (PDT-effort) /increased efficiency of the anaerobic system. These results could be a result of an improvement in anaerobic threshold, specifically a decrease in muscle $\mathrm{pH}$, phosphocreatine, ATP activation of anaerobic glycolysis due to a significant involvement of aerobic metabolism and the enhancement of the $\mathrm{VO}_{2 \max }$ and aerobic enzyme activity. [17]

These authors' hypothesis was partially correct as NZASA physical performance results at the start of the season were either inferior or superior compared with respective RU athletes of similar age groups from other nations. After 31weeks, compared to ERUA and SARU athletes, NZASA weighed less, had lower skinfold measurements, and were, generally, faster and stronger while being 'fatigue-resistant' and required less effort to attain positive physical performance results during high-intensity activity.

\section{Conclusion}

This study is the first to provide evidence of large to small physical performance enhancement in Academy studentathletes over a 31-week Premier RU League season with trivial increases in body weight and skinfold measurements yet without the detrimental effects of fatigue/overtraining. As such, team staff (coaches, sports medicine and sports science professionals) should appreciate that gains in anthropometrical characteristics do not necessarily lead to negative physical performance (acceleration, anaerobic endurance/threshold, lower body power, speed, and/or upper body strength) variables. This data will hopefully assist respective staff of Tier $2 \mathrm{RU}$ nations (as defined by the International Rugby Board/World Ruby) a greater understanding regarding the anthropometrical and physical performance demands required to complete against elite/Tier 1 RU nations.

Disclosure statement: None of the authors have/had a financial or personal conflict of interest with any person(s) and/or organisation(s) and did not influence the data/work presented in this paper.

\section{References}

1. Duthie G, Pyne D, Hooper S. Applied physiology and game analysis of rugby union. Sports Med 2003;33(13):973-991. [doi: 10.2165/00007256-200333130-00003]

2. Parker ZA. Factors associated with success in South African Rugby Union. Cape Town: University of Cape Town, 2013. URL: https://open.uct.ac.za/handle/11427/2760
3. Eston RG, Hawes MR, Martin AD, et al. Human body composition. In: Eston R, Reilly T, eds. Kinanthropometry and exercise physiology laboratory manual: Tests, procedures and data. Vol. 1 Anthropometry. 3rd ed. London: Routledge; 2009: 3-53.

4. Tanner R, Gore CJ, eds. Physiological tests for elite athletes. Australian Institute of Sport. 2nd ed. 2013; Chapter 11: 167-197.

5. Cohen J. A power primer. Psychol Bull 1992;112(1):155-159. [PMID:19565683]

6. Appleby B, Newton RU, Cormie P. Changes in strength over a 2 -year period in professional rugby union players. J Strength Cond Res 2012;26(9):2538-2546. [doi: 10.1519/JSC.0b013e31823f8b86]

7. Till K, Tester E, Jones B, et al. Anthropometric and physical characteristics of english academy rugby league players. J Strength Cond Res 2014;28(2):319-327. [doi: 10.1519/JSC.0b013e3182a73c0e]

8. Smart DJ, HopkinsWG, GillND. Difference and changes in the physical characteristics of professional and amateur rugby union players. J Strength Cond Res 2013;27(11):3033-3044. [doi: 10.1519/JSC.0b013e31828c26d3]

9. Vaz L, Vasilica I, Carreras D,et al. Physical fitness profiles of elite under-19 rugby union players. J Sports Med Phys Fitness 2016;56(4):415-421. [PMID: 25651896]

10. Darrall-Jones JD, Jones B, Till K. Anthropometric and physical profiles of English Academy Rugby Union players. J Strength Cond Res 2015;29(8):2086-2096. [doi: 10.1519/JSC.0000000000000872]

11. Lombard WP, Durandt JJ, Masimla H, et al. Changes in body size and physical characteristics of South African under-20 rugby union players over a 13-year period. J Strength Cond Res 2015;29(4):980-988. [doi: 10.1519/JSC.00000000000000724]

12. Mero A, Luhtanen P, Vitasalo JT, et al. Relationships between the maximal running velocity, muscle fiber characteristics, force production and force relaxation of sprinters. Scand J Sports Sci 1981;3(1):16-22.

13. Cronin JB, Hansen KT. Strength and power predictors of sports speed. J Strength Cond Res 2005;19(2):349-357. [doi: 10.1519/14323.1]

14. Hoffman JR, Kang J. Strength changes during an in-season resistance-training program for football. J Strength Cond Res 2003;17(1):109-114. [PMID: 12580665]

15. Baker DG. 10-year changes in upper body strength and power in elite professional rugby league players--the effect of training age, stage, and content. J Strength Cond Res 2013;27(2):285-292. [doi: 10.1519/JSC.0b013e318270fc6b].

16. Argus CK, Gill ND, Keogh JW. Characterization of the differences in strength and power between different levels of competition in rugby union athletes. J Strength Cond Res 2012;26(10):2698-2704. [doi: 10.1519/JSC.0b013e318241382a]

17. Spencer M, Bishop D, Dawson B, et al. Physiological and metabolic responses of repeated-sprint activities: specific to field-based team sports. Sports Med 2005;35(12):1025-1044. [PMID: 16336007] 